\title{
Composted versus Raw Olive Mill Waste as Substrates for the Production of Medicinal Mushrooms: An Assessment of Selected Cultivation and Quality Parameters
}

\author{
Georgios I. Zervakis, ${ }^{1}$ Georgios Koutrotsios, ${ }^{1}$ and Panagiotis Katsaris ${ }^{2}$ \\ ${ }^{1}$ Agricultural University of Athens, Laboratory of General and Agricultural Microbiology, Iera Odos 75, 11855 Athens, Greece \\ ${ }^{2}$ Hellenic Agricultural Organization-Demeter, Institute of Kalamata, Lakonikis 85, 24100 Kalamata, Greece \\ Correspondence should be addressed to Georgios I. Zervakis; zervakis@aua.gr
}

Received 4 April 2013; Accepted 3 July 2013

Academic Editor: Nuri Azbar

Copyright ( 92013 Georgios I. Zervakis et al. This is an open access article distributed under the Creative Commons Attribution License, which permits unrestricted use, distribution, and reproduction in any medium, provided the original work is properly cited.

\begin{abstract}
Two-phase olive mill waste (TPOMW, "alperujo") is a highly biotoxic sludge-like effluent of the olive-oil milling process with a huge seasonal production. One of the treatment approaches that has so far received little attention is the use of TPOMW as substrate for the cultivation of edible mushrooms. Fifteen fungal strains belonging to five species (Basidiomycota), that is, Agrocybe cylindracea, Pleurotus cystidiosus, P. eryngii, P. ostreatus, and P. pulmonarius, were evaluated for their efficacy to colonize media composed of TPOMW, which was used either raw or composted in mixtures with wheat straw in various ratios. Qualified strains exhibited high values of biological efficiency (e.g., $120-135 \%$ for Pleurotus spp. and $125 \%$ for A. cylindracea) and productivity in subsequent cultivation experiments on substrates supplemented with $20-40 \%$ composted TPOMW or $20 \%$ raw TPOMW. Only when supplementation exceeded 60\% for raw TPOMW, a negative impact was noted on mushroom yields which could be attributed to the effluent's toxicity (otherwise alleviated in the respective composted TPOMW medium). Earliness and mushroom size as well as quality parameters such as total phenolic content and antioxidant activity did not demonstrate significant differences versus the control wheat-straw substrate. The substrates hemicellulose content was negatively correlated with mycelium growth rates and yields and positively with earliness; in addition, cellulose: lignin ratio presented a positive correlation with mycelium growth and mushroom weight for A. cylindracea and with earliness for all species examined. TPOMW-based media revealed a great potential for the substitution of traditional cultivation substrates by valorizing environmentally hazardous agricultural waste.
\end{abstract}

\section{Introduction}

The disposal of wastes and by-products generated by the olive-oil industry are linked with major environmental repercussions because of their high organic content, composition, and seasonality of production. For reducing the huge volumes of olive mill wastewater produced by the widespread three-phase centrifugal systems, two-phase decanters were introduced. In this type of olive mills, the malaxed olive paste is separated from the oily phase with the addition of limited quantities of water. Hence, the only by-product of the extraction process is a sludge-like pomace, known as twophase olive mill waste (TPOMW or "alperujo"). Nevertheless, TPOMW's properties, that is, moisture content of $60-65 \%$, acidic $\mathrm{pH}$, high content of lipids, and polyphenolics, still pose serious problems related with its effective management and safe disposal $[1,2]$.

Several studies dealt with TPOMW detoxification through the development of the appropriate solid-state fermentation methodologies and the addition of suitable cocomposting materials for coping with the particular structure of this effluent $[3,4]$. Pertinent results and conclusions were further expedited by the evaluation of the final products (TPOMW-based composts) as organic amendments in the cultivation of various crops and for the suppression of soilborne plant pathogens [5-8]. Apart from the exploitation of mixed microbial communities present throughout the composting process, the potent lignin-degrading enzymatic system of selected wood-rot basidiomycetes was also used to decrease TPOMW phenolics and phytotoxicity [9-11]. 
Despite the fact that degradation of olive mill effluents was exhibited in the past by various species of edible ligninolytic macrofungi [12-14], a rather limited amount of information is available on the evaluation of wastes and byproducts of the olive-oil industry as substrates for mushroom production. Previous studies focused mainly on the use of olive mill wastewater for Pleurotus species cultivation either as the sole ingredient [15], as wetting agent of conventional wheat straw media $[16,17]$, or even as the main substrate constituent together with extracted olive-press cake [18]. Similarly, Altieri et al. [19] used olive mill by-products from three-phase systems for commercial-scale cultivation of the button mushroom Agaricus bisporus. On the other hand, pertinent exploitation of TPOMW has only recently attracted research interest $[20,21]$ demonstrating that this approach could provide promising alternatives for the valorization of this notorious effluent, especially if the ever growing trend of employing two-phase decanters in Mediterranean countries is taken into consideration.

Pleurotus ostreatus, $P$. eryngii, $P$. pulmonarius, and $P$. cystidiosus are among the most commonly occurring Pleurotus species and they all present a wide geographical distribution in most temperate regions of the world [22, 23]. Their cultivation is very popular since they can be produced on a large variety of plant residues and agroindustrial by-products [24-27]. On the other hand, Agrocybe cylindracea is also a widely distributed wood-rotting fungus [28] reported to grow on a wide range of lignocellulosic substrates [25, 29], and it is among the best candidates for diversifying commercial mushroom markets. In addition, all mentioned edible mushroom species have drawn research attention due to their content in bioactive compounds including antioxidants, vitamins, $\beta$-glucans, and lectins presenting immunostimulating and antitumor activities [30-33]. However, an important prerequisite for further development of their cultivation is the increase in productivity through the exploitation of novel cheap substrates in order to support a financially viable agroindustrial activity.

The aim of this study was to examine the use of several TPOMW-based media as substrates for the cultivation of five choice edible mushroom species through the evaluation of the appropriate production and quality parameters. In addition, it was investigated whether TPOMW subjected to a composting pretreatment process could further enhance mushroom productivity without any negative impact on quality aspects.

\section{Materials and Methods}

2.1. Organisms. Fifteen fungal strains (assigned in five species of the phylum Basidiomycota) were examined in the frame of the present study:

(1) Agrocybe cylindracea, strains IK10 (Greece), IK21 (Greece), and SIEF0834 (China);

(2) Pleurotus cystidiosus, strains LGAM P50 (Greece), LGAM P100 (Greece), and D415 (USA);
(3) P. eryngii, strains LGAM63 (Greece), LGAM101 (Greece), and UPA10 (Italy);

(4) P. ostreatus, strains LGAM60 (Greece), LGAM106 (Greece), and LGM850402 (Hungary);

(5) P. pulmonarius, strains LGAM10 (Greece), LGAM26 (Greece), and LGM850403 (France).

All strains tested were isolated from the wild, they were routinely maintained on potato dextrose agar (PDA, Difco), and they are preserved in the fungal Culture Collection of the Laboratory of General and Agricultural Microbiology (Agricultural University of Athens, Greece).

2.2. Preparation of TPOMW-Based Media and Assessment of Mycelium Growth Rates. Two-phase olive mill waste (TPOMW, deriving from the respective olive-oil extraction process) was obtained from an olive mill located in the city of Kalamata (Peloponnese, southwest Greece), and it was provisionally stored at $4^{\circ} \mathrm{C}$. Apart from the use of raw TPOMW, TPOMW which was previously subjected to a controlled aerobic thermophilic process (composting) was also evaluated. Before composting, olive leaves were added to raw TPOMW as a bulking agent (for improving porosity and facilitating aeration) at a $10 \% \mathrm{w} / \mathrm{w}$ ratio. Composting was performed by means of a static pile placed within a wooden container $\left(0.16 \mathrm{~m}^{3}\right.$ volume $)$. Aeration was passive from bottom to top of the pile, and a $2 \mathrm{~cm}$ thick layer of polyurethane insulation was used to cover perimetrically the container for minimizing temperature losses. The moisture within the pile was kept at $55-65 \%$ of its water-holding capacity by adding water at regular intervals throughout the composting process. Turnings were performed at the end of each thermophilic phase by manually emptying and refilling the container. Temperature and $\mathrm{pH}$ values were monitored during the entire process by probes positioned randomly within the pile. Composting was performed for a period of ca. 60 days followed by a 30 days curing period; the active composting phase was considered terminated when the temperature of the pile was close to ambient and (despite turning) further reheating did not occur.

For determining fungal strains efficiency to colonize substrates, three different media were prepared as follows: raw TPOMW and wheat straw (WS) were mixed in w/w ratios of $60: 40,40: 60$, and $20: 80$. In addition, three other substrates were prepared by mixing WS with composted TPOMW (in the same w/w ratios as in the previous case), while a WS-based substrate (without adding TPOMW) was used as control.

Measurements of linear growth rates were performed to test the ability of these substrates to support growth of the mushroom strains under study. For this purpose, glass "race" tubes $(200 \times 30 \mathrm{~mm})$ were used as described by Zervakis et al. [34]; three replicates per strain and substrate were inoculated with one agar-plug, taken from the actively growing periphery of a fungal colony developing on PDA (Difco). Incubation of cultures was carried out at $26^{\circ} \mathrm{C}$. Mycelium linear growth was recorded daily as previously described [34]. 
2.3. Preparation of Spawn and Mushroom Cultivation Substrates. For inoculation of mushroom cultivation substrates, grain spawn for four selected (on the basis of their growth rates as evidenced in the previous experiment) strains representing $A$. cylindracea, $P$. eryngii, $P$. ostreatus, and $P$. pulmonarius was prepared as described by Philippoussis et al. [25].

The comparative assessment of fungal strains in the "race" tubes experiment led also to the qualification of seven cultivation substrates for further evaluation: raw and (independently) composted TPOMW in $60: 40,40: 60$, and $20: 80$ (w/w) mixtures with WS, plus a plain WS-based substrate serving as control. In each substrate, calcium carbonate was added $(2 \% \mathrm{w} / \mathrm{w}), \mathrm{pH}$ and moisture content were adjusted to 6.1 and $60-65 \%$, respectively, and it was then supplemented by $5 \%$ wheat bran (w/w, in terms of dry weight). Three replicates per substrate and strain were used. Polypropyleneautoclavable bags were filled with substrate and were sterilized for one hour at $1.1 \mathrm{~atm}$. Spawn inoculation was carried out along the central vertical axis of the bag, at a rate of $3 \%(\mathrm{w} / \mathrm{w})$, by using sterile hollow copper tubes. Colonization of the substrates and fructification took place in growth chambers as previously described [25]. In brief, incubation of the cultures within the tightly closed bags took place at $25^{\circ} \mathrm{C}$ in the dark; when substrates were fully colonized, relative air humidity was set at $95 \pm 2 \%$, temperature was decreased by $7^{\circ} \mathrm{C}$, and illumination was provided $\left(700 \mathrm{lux} \mathrm{m}^{-2}, 12 \mathrm{~h}\right.$ day $^{-1}$ with fluorescent lamps). After primordium formation, $\mathrm{CO}_{2}$ levels were maintained at less than $1200 \mathrm{ppm}$, relative humidity at $80 \pm 2 \%$, and illumination at $1000 \mathrm{lux} \mathrm{m}^{-2}\left(12 \mathrm{~h} \mathrm{day}^{-1}\right.$ with fluorescent lamps).

2.4. Crop Yield Parameters. Three mushroom production flushes for $P$. ostreatus and $P$. pulmonarius and two flushes for $P$. eryngii and $A$. cylindracea were collected during the cropping period. Mature basidiomata were harvested at the same time each day, counted and weighted. Among the parameters evaluated to test the suitability of the substrates under study for the cultivation of the four mushroom species were (a) earliness, defined as the time elapsed between the day of inoculation and the day of primordia formation, (b) yield, expressed as fresh weight of mushrooms harvested, (c) biological efficiency (BE), calculated as the percentage ratio of fresh mushrooms weight over the dry weight of the substrate, (d) productivity, expressed as the ratio of yield over the number of cultivation days, and (e) average mushroom weight, measured as the ratio of the total mushroom yield over the number of individual basidiomata produced.

2.5. Chemical Analyses and Phytotoxicity Tests. Measurements of $\mathrm{pH}$ were performed with a Scott Geräte TR156 pHmeter by using a 1:2 sample to water ratio. Total nitrogen of the substrates used was determined by wet digestion of finely ground $0.3 \mathrm{~g}$ samples in concentrated $\mathrm{H}_{2} \mathrm{SO}_{4}$ (Kjeldahl digestion) followed by steam distillation under alkaline conditions and titrimetric determination of the ammonium-N collected in boric acid. Total carbon measurements were performed by dry heating (ashing) at $530^{\circ} \mathrm{C}$ for $8 \mathrm{~h}$. First, the organic matter content was estimated by measuring the weight loss of the sample following the heating process, whereas total carbon was calculated by multiplying the organic content with a factor of 0.58 . Acid detergent fiber (ADF), lignin, and cellulose were determined by the method of van Soest and Wine [35], while hemicellulose was estimated as the difference between ENDF (neutral detergent fiber with enzyme modification) and $\mathrm{ADF}[36,37]$. The rest of the analyses (unless otherwise specified) were performed as described by Ntougias et al. [38].

For measurements of total phenolics content, cultivation substrates and mushroom samples were freeze-dried and then powders were analyzed by the Folin-Ciocalteu method [39]. Absorbance was measured at $750 \mathrm{~nm}$ by using a U-2001 spectrophotometer (Hitachi Instruments Inc., USA). Gallic acid was used as standard for quantification.

For establishing DPPH scavenging capacity, freeze-dried mushroom powders were mixed with $1 \mathrm{~mL}$ methanol, vortexed for $5 \mathrm{~min}$, and then centrifuged for $10 \mathrm{~min}$ at $12000 \mathrm{rpm}$. The antioxidant activity of supernatants was measured by using a $1 \mathrm{mM}$ DPPH (2,2-diphenyl-1-picrylhydrazyl) solution as previously described [40] and by determining absorbance at $515 \mathrm{~nm}$ after $30 \mathrm{~min}$ incubation.

The seed germination index (GI) was estimated according to Zucconi et al. [41] protocol by using 25 cress (Lepidium sativum L.) seeds per sample; these were placed onto a filter paper moistened either with the sample (1:9 TPOMW : water, v/v) or with water (control, GI:100\%), and they were incubated in a Petri dish for $3 \mathrm{~d}$ in the dark.

2.6. Data Analysis. All experiments were performed in triplicate unless otherwise stated. Results are expressed as mean values \pm standard errors. Analysis of variance was conducted by Gabriel's $t$-test at 5\% level of probability to compare mean values. Pearson's correlation coefficient was employed to analyze relationships between variables. The SPSS (ver. 18) software was used for all statistical analyses.

\section{Results}

3.1. Composting of TPOMW. Composting of the TPOMW material exhibited a rather sharp increase in temperature values reaching levels of $57^{\circ} \mathrm{C}$ within one-two weeks from the start of the process (Figure 1). The first thermophilic phase lasted ca. three weeks, and it was followed by the first turning. Better aeration conditions combined with a higher availability of nutrients led to another rise in temperature at values exceeding $50^{\circ} \mathrm{C}$ (after one week from turning) and to a second thermophilic phase which lasted for 15 days. The second turning was performed at about the end of the fifth week and was followed by another increase in temperature at ca. $43^{\circ} \mathrm{C}$. The last thermophilic phase had a duration of approximately two weeks, and it was followed by the third turning at the end of the seventh week; this intervention resulted in a low temperature raise $\left(30^{\circ} \mathrm{C}\right)$, and then a fourth and final turning was performed without any effect in the temperature of the pile indicating thus the end of the process. On the other hand, $\mathrm{pH}$ values presented a fast increase from 5.4 to 8.1 within the first four-five weeks 


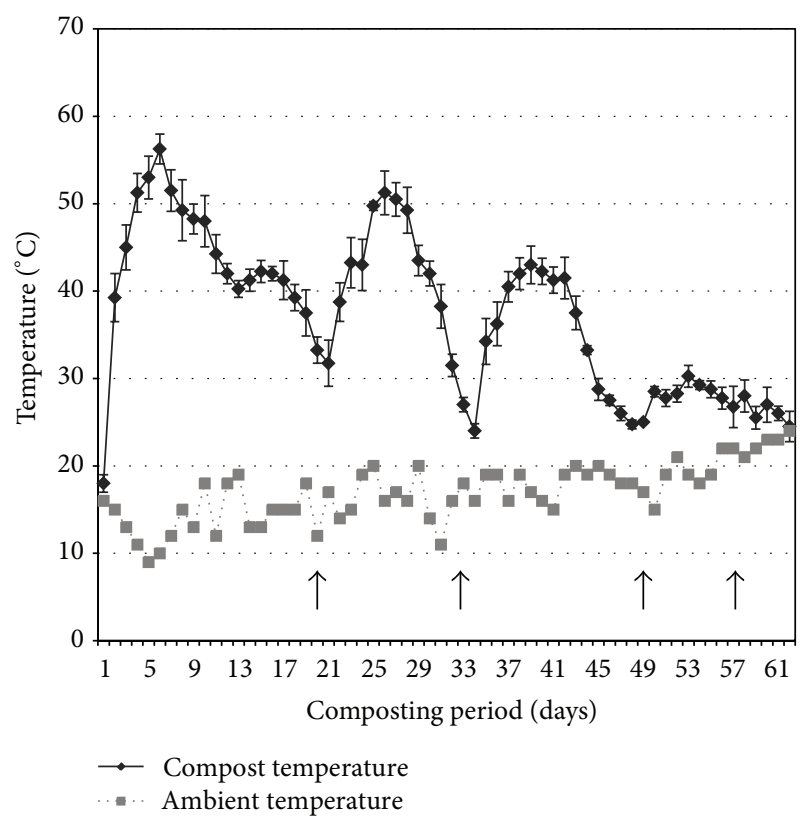

FIgURE 1: Temperature fluctuations during the TPOMW composting process in the compost pile and in the surrounding environment. $Y$-axis values represent temperatures and $X$-axis values represent measurements taken during the composting process and for a period of 60 days. Vertical arrows indicate the time of pile-turning interventions.

of the composting period, and were then stabilized at levels of 8.2-8.3 for the rest of the process (Table 1). Electrical conductivity rose slightly $\left(1.68 \mathrm{mS} \mathrm{cm}^{-1}\right)$ as anticipated in the course of composting, whereas organic matter decreased by less than $10 \%$ (reaching values of approximately $88 \%$ ). In addition, $\mathrm{C}: \mathrm{N}$ ratio decreased considerably (i.e., 22) taking into account that no external nitrogen supplementation was provided during the process. Similarly, lignin, hemicellulose, and cellulose contents of raw TPOMW were reduced by ca. $9 \%, 40 \%$, and $21 \%$, respectively, in the final composted material. Finally, phytotoxicity decreased substantially from very high levels in both raw and prior to composting substrates (GI\%: 20-24) to low values (comparable to the water control) for composted TPOMW (GI\%: 88). The results of the analyses of raw and composted TPOMW (before and after composting) are presented in Table 1. For all cultivation substrates prepared, their content in $\mathrm{C}$ and $\mathrm{N}$ (before and after wheat bran amendment) as well as in lignin, hemicellulose, and cellulose was measured prior to inoculation with the selected fungi (Table 2). Noteworthy were the considerably lower values of $\mathrm{C}: \mathrm{N}$ ratios (in respect to wheat straw) obtained by high TPOMW supplementation especially in the case of composted materials, for example, 80 versus 29 . In parallel, lignin and cellulose contents presented also high differences in TPOMW-rich substrates when compared to the control treatment.

3.2. Mycelium Growth Rates and Earliness in "Race" Tubes Experiments. Prior to this study screening experiments with
TABLE 1: Properties of raw two-phase olive mill waste (TPOMW), of TPOMW (plus olives leaves) prior to composting, and of TPOMW after composting.

\begin{tabular}{|c|c|c|c|}
\hline & $\begin{array}{c}\text { Raw } \\
\text { TPOMW }\end{array}$ & $\begin{array}{l}\text { TPOMW prior } \\
\text { to composting }\end{array}$ & $\begin{array}{c}\text { TPOMW after } \\
\text { composting }\end{array}$ \\
\hline$\overline{\mathrm{pH}}$ & 5.1 & 5.92 & 8.15 \\
\hline $\mathrm{EC}^{1}\left(\mathrm{mS} \mathrm{cm}^{-1}\right)$ & 1.08 & 1.15 & 1.68 \\
\hline Total C (\%) & 53.64 & 51.07 & 42.47 \\
\hline Total N (\%) & 1.31 & 1.45 & 1.96 \\
\hline $\mathrm{C}: \mathrm{N}$ & 40.95 & 35.22 & 21.67 \\
\hline $\operatorname{TOM}^{2}(\%)$ & 96.21 & 94.31 & 87.88 \\
\hline Ash (\%) & 3.47 & 4.12 & 4.76 \\
\hline $\mathrm{P}\left(\mathrm{g} \mathrm{kg}^{-1}\right)$ & 1.01 & 1.08 & 1.23 \\
\hline $\mathrm{K}\left(\mathrm{g} \mathrm{kg}^{-1}\right)$ & 15.4 & 16.3 & 21.34 \\
\hline Lignin $\left(\mathrm{g} \mathrm{kg}^{-1}\right)$ & 351 & 343 & 318 \\
\hline Hemicellulose $\left(\mathrm{g} \mathrm{kg}^{-1}\right)$ & 380 & 341 & 226 \\
\hline Cellulose $\left(\mathrm{g} \mathrm{kg}^{-1}\right)$ & 211 & 208 & 167 \\
\hline $\mathrm{GI}^{3}(\%)$ & 20 & 24 & 88 \\
\hline
\end{tabular}

EC: electrical conductivity.

${ }^{2}$ TOM: total organic matter.

${ }^{3}$ GI: germination index.

several mushroom species (i.e., Agrocybe cylindracea, Auricularia auricula-judae, Lentinula edodes, Pleurotus cystidiosus, $P$. eryngii, $P$. ostreatus, and $P$. pulmonarius) were conducted for qualifying those which could colonize TPOMW-based substrates (data not shown). Subsequent results excluded the use of A. auricula-judae and L. edodes as well as further experimentation with substrates composed entirely of TPOMW or of $80: 20(\mathrm{w} / \mathrm{w})$ mixture with WS since the growth of most strains could not be adequately supported. This prescreening process was adopted because of the significant variability in the efficacy demonstrated by different species/strains in colonizing olive mill wastes $[13,42]$.

In the frame of the present work, 15 fungal strains assigned to five mushroom species were evaluated for their ability to colonize TPOMW either raw (in different ratios in mixtures with wheat straw) or pretreated (composted) in "race" tubes experiments (Table 3). In all cases, substrates containing composted TPOMW performed notably better than the respective raw TPOMW treatments. In one particular case (P. cystidiosus), the latter substrate did not even permit mycelium growth at the $60: 40$ ratio, whereas the composted material provided growth rates values equivalent to those obtained by raw TPOMW in lower concentrations (e.g., $1.22-1.40$ and $1.71-1.91 \mathrm{~mm} \mathrm{day}^{-1}$ in raw TPOMW $40 \%$ and $20 \%$, respectively, versus $1.46-1.56 \mathrm{~mm} \mathrm{day}^{-1}$ in composted TPOMW 60\%). In general, mycelium growth values in composted TPOMW were comparable to those measured for raw TPOMW media with lesser content in the effluent. Noteworthy was also that for all nine P. eryngii, P. ostreatus, and P. pulmonarius strains, the composted TPOMW $20 \%$ substrate performed significantly better than the straw (control) treatment, while the same observation could be made for A. cylindracea strains as well (albeit 
TABLE 2: Total carbon (C), nitrogen (N), lignin, hemicellulose, and cellulose contents (values expressed on a dry matter basis) of the substrates used for mushroom cultivation experiments.

\begin{tabular}{|c|c|c|c|c|c|c|c|}
\hline Substrates $^{1}$ & $\mathrm{C}^{2}(\%$ d.w. $)$ & $\mathrm{N}^{2}$ (\% d.w.) & $\mathrm{C}: \mathrm{N}^{2}$ & $\mathrm{C}: \mathrm{N}^{3}$ & $\operatorname{Lignin}^{2}\left(\mathrm{~g} \mathrm{~kg}^{-1}\right)$ & Hemicellulose $^{2}\left(\mathrm{~g} \mathrm{~kg}^{-1}\right)$ & Cellulose $^{2}\left(\mathrm{~g} \mathrm{~kg}^{-1}\right)$ \\
\hline WS & 44.15 & 0.43 & 102.67 & 79.78 & 191 & 218 & 370 \\
\hline TPOMW 20\% & 49.98 & 0.72 & 69.42 & 60.44 & 224 & 242 & 334 \\
\hline TPOMW 40\% & 47.79 & 0.89 & 53.70 & 46.12 & 261 & 288 & 305 \\
\hline TPOMW 60\% & 44.12 & 0.99 & 44.57 & 37.57 & 296 & 317 & 271 \\
\hline cTPOMW 20\% & 42.02 & 0.93 & 45.18 & 40.55 & 221 & 220 & 321 \\
\hline сTPOMW 40\% & 40.34 & 1.05 & 38.42 & 35.46 & 250 & 222 & 287 \\
\hline сTPOMW 60\% & 37.76 & 1.24 & 30.45 & 28.74 & 273 & 223 & 231 \\
\hline
\end{tabular}

WS: wheat straw; TPOMW: raw two-phase olive mill waste; cTPOMW: composted two-phase olive mill waste. Percentage values following TPOMW refer to its respective content $(\mathrm{w} / \mathrm{w})$ in the cultivation substrate.

${ }^{2}$ Values for substrates prior to any wheat bran amendment.

${ }^{3}$ Values after amendment of wheat bran.

TABle 3: Mycelium growth rates of 15 strains belonging to five mushroom species (P.cs: Pleurotus cystidiosus; P.er.: P. eryngii; P.os: P. ostreatus; P.pl: P. pulmonarius; A.cl: Agrocybe cylindracea) colonizing seven substrates (WS: wheat straw; TPOMW: raw two-phase olive mill waste; cTPOMW: composted two-phase olive mill waste) in "race-tube" experiments. Values ( $\mathrm{mm} /$ day) are expressed as means \pm standard errors of means, $n=3$. Lack of letters in common indicates statistically significant differences (Gabriel's $t$-test, $P<0.05$ ) for comparisons of treatment means between different strains (capital letters) and different substrates (lowercase letters).

\begin{tabular}{|c|c|c|c|c|c|c|c|c|}
\hline Species & Strain & WS & TPOMW 20\% & TPOMW 40\% & TPOMW 60\% & cTPOMW 20\% & сTPOMW 40\% & cTPOMW 60\% \\
\hline \multirow{3}{*}{ P.cs. } & LGAM50 & $2.28 \pm 0.21^{\mathrm{a} . \mathrm{F}}$ & $1.74 \pm 0.13^{\text {bcd.F }}$ & $1.22 \pm 0.07^{\mathrm{d} . G}$ & nd & $2.20 \pm 0.07^{\mathrm{ab} . \mathrm{G}}$ & $1.94 \pm 0.05^{\mathrm{abc.K}}$ & $1.46 \pm 0.05^{\text {cd.G }}$ \\
\hline & LGAM100 & $1.99 \pm 0.12^{\mathrm{ab} . \mathrm{F}}$ & $1.71 \pm 0.07^{\mathrm{abc} . \mathrm{F}}$ & $1.40 \pm 0.03^{\text {c.G }}$ & nd & $2.14 \pm 0.09^{\mathrm{a} . \mathrm{G}}$ & $2.05 \pm 0.11^{\mathrm{a} . \mathrm{K}}$ & $1.56 \pm 0.12^{\text {bc.G }}$ \\
\hline & D415 & $2.55 \pm 0.10^{\mathrm{a} . \mathrm{F}}$ & $1.91 \pm 0.07^{\text {bc.F }}$ & $1.31 \pm 0.06^{\mathrm{e} . \mathrm{G}}$ & nd & $2.23 \pm 0.11^{\mathrm{ab} . \mathrm{G}}$ & $1.79 \pm 0.08^{\text {cd.K }}$ & $1.47 \pm 0.06^{\mathrm{de} . \mathrm{G}}$ \\
\hline \multirow{3}{*}{ P.er. } & LGAM101 & $6.42 \pm 0.36^{\text {cd.CD }}$ & $7.49 \pm 0.32^{\text {bc.CD }}$ & $6.46 \pm 0.21^{\text {cd.D }}$ & $5.38 \pm 0.21^{\mathrm{d} . \mathrm{D}}$ & $8.72 \pm 0.12^{\mathrm{a} . \mathrm{D}}$ & $8.39 \pm 0.08^{\mathrm{ab} . \mathrm{EF}}$ & $7.45 \pm 0.16^{\mathrm{bc} . \mathrm{C}}$ \\
\hline & LGAM63 & $6.26 \pm 0.24^{\text {d.CD }}$ & $7.26 \pm 0.14^{\mathrm{bc} . \mathrm{D}}$ & $6.42 \pm 0.20^{\mathrm{d} . \mathrm{D}}$ & $5.05 \pm 0.17^{\mathrm{e} . \mathrm{D}}$ & $8.51 \pm 0.08^{a . D}$ & $7.93 \pm 0.08^{\mathrm{ab} . \mathrm{F}}$ & $7.05 \pm 0.12^{\text {cd.CD }}$ \\
\hline & UPA10 & $5.58 \pm 0.30^{\mathrm{c.CD}}$ & $6.73 \pm 0.16^{\mathrm{b} . \mathrm{D}}$ & $5.37 \pm 0.13^{\mathrm{c.E}}$ & $5.37 \pm 0.28^{\mathrm{c} . \mathrm{D}}$ & $7.73 \pm 0.16^{\mathrm{a} . \mathrm{E}}$ & $7.28 \pm 0.14^{\text {ab.G }}$ & $6.61 \pm 0.10^{\text {b.D }}$ \\
\hline \multirow{3}{*}{ P.os. } & LGAM60 & $8.96 \pm 0.28^{\mathrm{d} . \mathrm{A}}$ & $9.94 \pm 0.27^{\mathrm{abc} . \mathrm{A}}$ & $9.06 \pm 0.10^{\mathrm{cd} . \mathrm{A}}$ & $7.68 \pm 0.17^{\mathrm{e} . \mathrm{AB}}$ & $10.67 \pm 0.11^{\mathrm{a} . \mathrm{A}}$ & $10.15 \pm 0.15^{\mathrm{ab} . \mathrm{A}}$ & $9.29 \pm 0.08^{\text {bcd.A }}$ \\
\hline & LGM850402 & $7.51 \pm 0.31^{\mathrm{c} . \mathrm{BC}}$ & $7.66 \pm 0.17^{\mathrm{bc} . \mathrm{CD}}$ & $7.31 \pm 0.21^{\text {cd.C }}$ & $6.38 \pm 0.15^{\text {d.C }}$ & $8.93 \pm 0.13^{\mathrm{a} . \mathrm{D}}$ & $8.82 \pm 0.14^{\mathrm{a} . \mathrm{DE}}$ & $8.55 \pm 0.07^{\mathrm{ab} . \mathrm{B}}$ \\
\hline & LGAM106 & $8.13 \pm 0.36^{\text {bcd.AB }}$ & $8.61 \pm 0.37^{\mathrm{abc} \cdot \mathrm{BC}}$ & $7.87 \pm 0.10^{\text {cd.BC }}$ & $7.07 \pm 0.19^{\mathrm{d} . \mathrm{BC}}$ & $9.70 \pm 0.09^{\mathrm{a} . C}$ & $9.03 \pm 0.05^{\mathrm{ab} . \mathrm{CD}}$ & $8.49 \pm 0.09^{\text {bc.B }}$ \\
\hline \multirow{3}{*}{ P.pl. } & LGAM26 & $8.90 \pm 0.15^{\mathrm{b} . \mathrm{A}}$ & $9.36 \pm 0.25^{\mathrm{ab} . \mathrm{AB}}$ & $8.65 \pm 0.26^{\mathrm{b} . \mathrm{AB}}$ & $7.61 \pm 0.15^{\mathrm{c} . \mathrm{AB}}$ & $10.04 \pm 0.10^{\mathrm{a} . \mathrm{BC}}$ & $9.42 \pm 0.11^{\mathrm{ab} . \mathrm{BC}}$ & $8.92 \pm 0.11^{\text {b.AB }}$ \\
\hline & LGAM10 & $9.28 \pm 0.29^{\text {bc.A }}$ & $10.05 \pm 0.15^{\mathrm{ab} . \mathrm{A}}$ & $9.01 \pm 0.14^{\text {c.A }}$ & $8.07 \pm 0.15^{\mathrm{d} . \mathrm{A}}$ & $10.64 \pm 0.16^{\mathrm{a} . \mathrm{AB}}$ & $9.99 \pm 0.11^{\mathrm{ab} . \mathrm{AB}}$ & $9.38 \pm 0.10^{\text {bc.A }}$ \\
\hline & LGAM580403 & $9.08 \pm 0.13^{\text {bc.A }}$ & $9.13 \pm 0.22^{\text {bc.AB }}$ & $8.82 \pm 0.08^{\mathrm{c} . \mathrm{A}}$ & $7.23 \pm 0.17^{\mathrm{d} . \mathrm{AB}}$ & $10.02 \pm 0.11^{\mathrm{a} . \mathrm{BC}}$ & $9.68 \pm 0.08^{\mathrm{ab} . \mathrm{AB}}$ & $8.89 \pm 0.10^{\text {c.AB }}$ \\
\hline \multirow{3}{*}{ A.cl. } & IK10 & $4.35 \pm 0.20^{\text {bc. } \mathrm{E}}$ & $4.27 \pm 0.20^{\text {c.E }}$ & $3.36 \pm 0.10^{\mathrm{d} . \mathrm{F}}$ & $2.69 \pm 0.13^{\mathrm{d} . \mathrm{E}}$ & $5.65 \pm 0.15^{\mathrm{a} . \mathrm{F}}$ & $5.11 \pm 0.12^{\mathrm{ab} . \mathrm{HI}}$ & $4.32 \pm 0.13^{\text {c.EF }}$ \\
\hline & LGAM281 & $5.38 \pm 0.13^{\mathrm{ab} . \mathrm{DE}}$ & $5.04 \pm 0.12^{\text {bc. E }}$ & $3.92 \pm 0.11^{\mathrm{d} . \mathrm{F}}$ & $3.18 \pm 0.14^{\mathrm{e} . \mathrm{E}}$ & $5.87 \pm 0.10^{\mathrm{a} . \mathrm{F}}$ & $5.53 \pm 0.10^{\mathrm{ab} . \mathrm{H}}$ & $4.62 \pm 0.13^{\mathrm{c.E}}$ \\
\hline & SIEF0834 & $5.15 \pm 0.15^{\mathrm{a} . \mathrm{DE}}$ & $4.80 \pm 0.18^{\mathrm{a} . \mathrm{E}}$ & $3.48 \pm 0.12^{\text {b.F }}$ & $2.51 \pm 0.10^{\mathrm{c.E}}$ & $5.36 \pm 0.12^{\mathrm{a} . \mathrm{F}}$ & $4.89 \pm 0.10^{\mathrm{a} . \mathrm{I}}$ & $3.81 \pm 0.14^{\mathrm{b} . \mathrm{F}}$ \\
\hline
\end{tabular}

differences were not statistically significant in this particular case). Raw TPOMW 60\% was the worst performing medium in the course of this evaluation.

As far as the behavior of individual species is concerned, $P$. cystidiosus strains were the poorest performers by presenting growth rates as low as $1.22 \mathrm{~mm} \mathrm{day}^{-1}$ or no growth at all at raw TPOMW (40:60 and 60:40 mixtures, resp.). On the other hand, the fastest colonizers were P. pulmonarius and
P. ostreatus; they performed significantly better than the rest of the species examined in all substrates tested by presenting values as high as $10.02-10.64$ and $8.93-10.67 \mathrm{~mm} \mathrm{day}^{-1}$, respectively, in the composted TPOMW 20:80 medium. Furthermore, $P$. eryngii provided relatively high growth rates in all TPOMW containing substrates. Of special interest was the fact that both 20:80 and 40:60 composted TPOMW ratios provided significantly better growth rates than the 


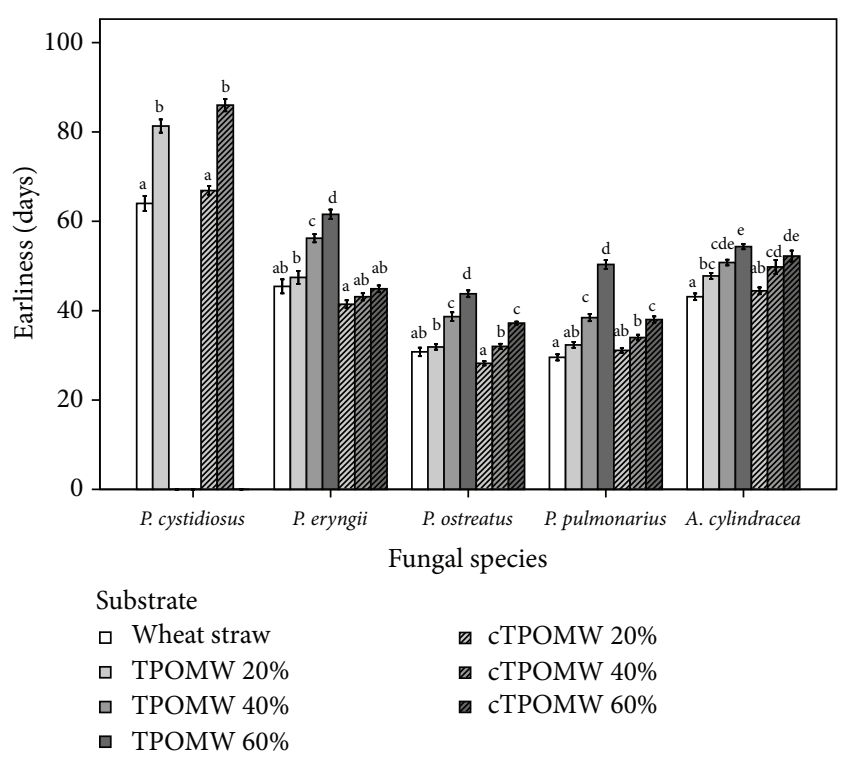

FIGURE 2: Earliness (time period elapsed from substrate inoculation until the appearance of basidiomata primordia) for five mushroom species colonizing seven substrates in "race-tube" experiments. Values (days) from three strains per species were pooled and results are expressed as means \pm standard errors of means, $n=9$. Lack of letters in common indicates statistically significant differences (Gabriel's $t$-test, $P<0.05$ ) among substrates for each species examined.

straw substrate (7.28-8.72 versus 5.58-6.42 $\mathrm{mm} \mathrm{day}^{-1}$, resp.). Lastly, A. cylindracea mycelia supported well increased concentrations of TPOMW and even when grown at the $60: 40$ composted TPOWM medium, the values obtained were slightly lower than those from the control treatment (3.814.62 versus $4.35-5.38 \mathrm{~mm}$ day $^{-1}$, resp.).

Within the frame of the same experiment, the time period needed from substrate inoculation until mushroom initial formation was noted (Figure 2). P. ostreatus and $P$. pulmonarius strains were the first to form primordia in all substrates within a period of 25 to 40 days (with the exception of raw TPOMW 60\% where slightly longer periods were required). P. eryngii and $A$. cylindracea needed 40 to 60 days for primordia formation, whereas $P$. cystidiosus was significantly slower (in line with the low growth rates it produced) since it needed 60 to 90 days to produce mushroom initials. Statistical comparisons among different substrates for the same species demonstrated that wheat straw (control) and composted TPOWM 20\%, were the most suitable media for fast primordia formation in P. cystidiosus and A. cylindracea, while wheat straw (control), raw and composted TPOWM $20 \%$, and composted TPOMW 40\% provided the best results for $P$. eryngii, $P$. ostreatus, and $P$. pulmonarius.

3.3. TPOMW-Based Substrates Evaluated for Mushroom Cultivation. The results of the "race-tubes" experiment permitted the qualification of four (the best performing) strains from four out of the five species initially examined. Hence, with the exception of all $P$. cystidiosus strains which were considerably slower and failed to yield consistently mushroom primordia, the following strains were further evaluated in mushroom cultivation trials: P. eryngii LGAM101, P. ostreatus LGAM60, P. pulmonarius LGAM10, and A. cylindracea LGAM281. In addition, all six TPOMW containing substrates were further examined as regards their suitability to support mushroom production in comparison to the wheat-straw (control) substrate.

Strains of $P$. ostreatus and $P$. pulmonarius were those that formed mushroom primordia within the shortest time period after substrate inoculation (Table 4). Hence, their respective earliness values were 4 to 5 weeks, such short periods being observed when fungi colonized either the wheat straw or composted TPOMW 20\% substrates (26-30 days). However, these values for both $P$. ostreatus and $P$. pulmonarius were not significantly different from those noted in the other substrates examined (with the exception of raw TPOMW 60\%). In contrast, earliness for the other two species $P$. eryngii and A. cylindracea was significantly higher ranging from 37-47 days for the former to 38-44 days for the latter species. Again, wheat straw and composted TPOMW 20\% and 40\% substrates provided lower values in comparisons among different substrates for the same fungus albeit differences were not statistically significant.

The cropping period lasted 23-46 days for P. eryngii and A. cylindracea (two production flushes were obtained) and 30-52 days for $P$. ostreatus and $P$. pulmonarius (three production flushes). For $P$. eryngii, total yields ranged from 93 to $364 \mathrm{~g}$ with the respective BEs ranging from 31 to 120 (Table 4; Figure 3). Despite the fact that most comparisons among different substrates did not result in statistical significant differences due to the relatively high variation of means, the composted TPOMW $20 \%$ and $40 \%$ provided very high values in respect to most other treatments including the control (BEs: 120 versus 88). In contrast, raw TPOMW 60\% exhibited the lowest values within the lengthier cropping period (BE: 33 in 46 days as opposed to cropping periods of 23 days for composted TPOMW 20\%). On the other hand, P. ostreatus demonstrated yields of up to $410 \mathrm{~g}$ (BE: 135 ) in the composted TPOMW 20\% treatment which almost doubled the respective value provided by the control treatment (i.e., $213 \mathrm{~g}, \mathrm{BE}$ : 70). This particular substrate as well as composted TPOMW $40 \%$ performed significantly better than the rest examined for P. ostreatus; it is noteworthy that the wheat straw supported the lowest yield values among all substrates examined (except of the raw TPOMW 60\%) for this particular species albeit within a relatively shorter period. In addition, $P$. pulmonarius provided also its highest yields in the composted TPOMW 20\% (381 g and BE: 126); however, composted TPOMW 40\% and raw TPOMW 20\% presented also high and comparable $\mathrm{BE}$ values (116-117), although not significantly different from the control treatment (100). Only the raw TPOMW 60\% substrate performed significantly worse than wheat straw. Lastly, A. cylindracea demonstrated an exceptionally good adaptation to olive mill waste containing substrates since all TPOMW media (except of raw TPOMW 60\%) provided significantly higher yields and BE values in comparison to the control, that is, 291-378 $\mathrm{g}$ and BEs: $96-125$ versus $210 \mathrm{~g}$ and BE: 69. 


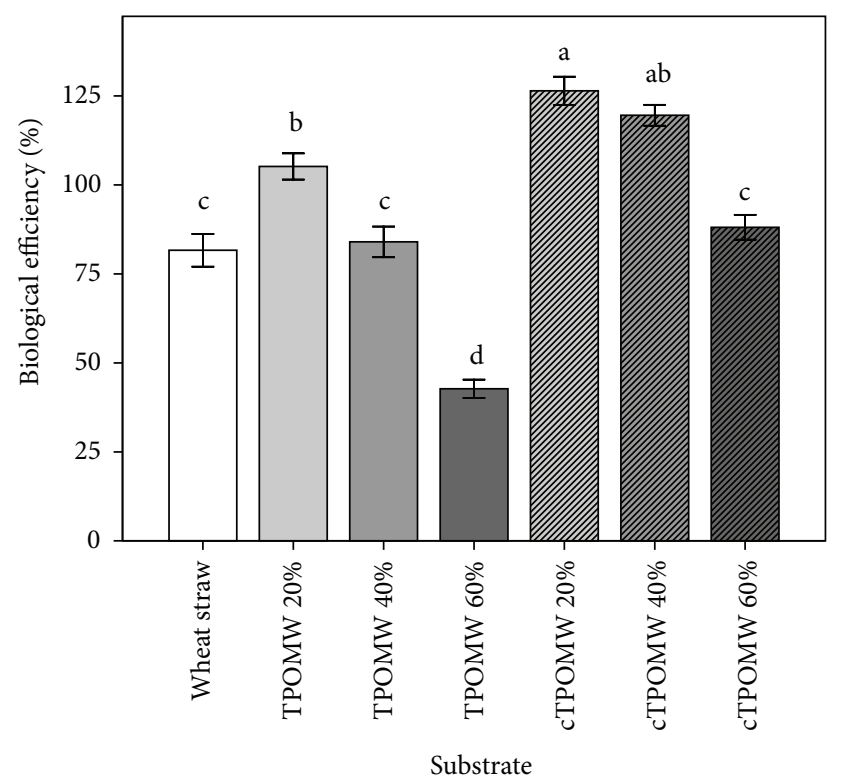

FIGURE 3: Biological efficiency (percentage ratio of fresh mushrooms weight over the dry weight of the respective substrate) for four mushroom species growing on seven cultivation substrates (TPOMW: raw two-phase olive mill waste; cTPOMW: composted two-phase olive mill waste). Values (\%) from four species were pooled and results are expressed as means \pm standard errors of means, $n=12$. Lack of letters in common indicates statistically significant differences (Gabriel's $t$-test, $P<0.05$ ) among the substrates examined.

As regards the distribution of yields per flush (Figure 4), P. eryngii and A. cylindracea exhibited a tendency to produce a larger part of their production in the first flush as the relative content of TPOMW increased in the substrate's composition; for example, for A. cylindracea $81 \%$ of the total production was harvested from the first flush in the composted TPOMW $60 \%$ as opposed to $74 \%$ in the composted TPOMW $20 \%$ substrate (77\% and $73 \%$ for the raw TPOMW $40 \%$ and $20 \%$ substrates, resp.). In the three-flush harvested species ( $P$. ostreatus and $P$. pulmonarius), approximately $10 \%$ (or less) of the total yield was obtained from the third flush, whereas the first flush generally contributed $65-75 \%$ of the total yield. Again, although not as evident as before the two of the richest in TPOMW substrates (raw 40\% and composted 60\%) produced a first flush production which accounted for 72$79 \%$ of the total in both species.

Substrates and fungal strains were also evaluated with respect to the weight of mushrooms obtained. P. eryngii produced the heaviest mushrooms among all species tested and this is in accordance to the habit of this particular fungus to form single basidiomata whereas the other three species form clusters composed of many basidiomata, each. Weight of individual P. eryngii mushrooms were significantly higher in the control treatment $(27 \mathrm{~g})$ followed by all other treatments which showed similar results (i.e., from 16 to $18 \mathrm{~g}$ ) (Table 4). In the cases of $P$. ostreatus and P. pulmonarius the size of mushrooms was not significantly different in comparisons between all treatments for the same species, and

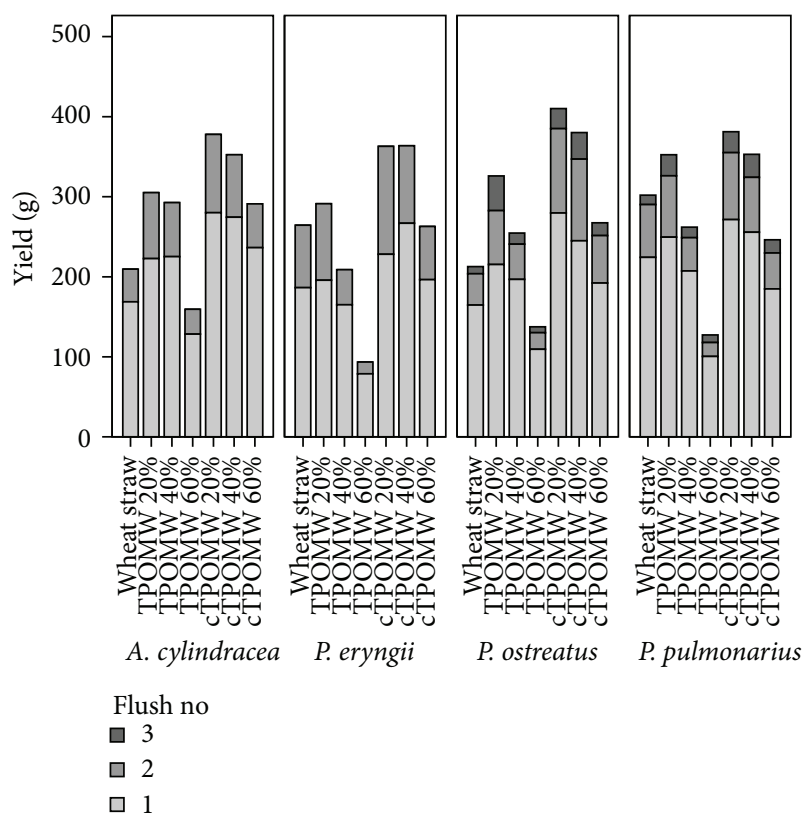

FIGURE 4: Distribution of mushroom yield per production flush for four mushroom species growing on seven cultivation substrates (TPOMW: raw two-phase olive mill waste; cTPOMW: composted two-phase olive mill waste). Values (g) are expressed as means, $n=3$.

hence the nature of the substrate did not seem to exert any particular influence. A. cylindracea basidiomata were similar in size when different TPOMW-based media were compared but again the control treatment supported the growth of larger mushrooms. Moreover, in comparisons performed among different species, $P$. ostreatus mushrooms produced from substrates composed of TPOMW (raw and composted) were heavier than those of P. pulmonarius and A. cylindracea.

Another cultivation parameter evaluated was productivity, which was defined as total mushroom yield produced within the particular cropping period for each substrate and species examined (Figure 5 ). The highest productivity was exhibited by the composted TPOMW 20\% and 40\% media, albeit not statistically significant in most cases. These two particular substrates supported high yields within relatively short time frames. Of importance was that the control medium (wheat straw) was notably inferior in productivity than composted TPOMW $20 \%$ by ca. three times in the case of A. cylindracea (statistically significant difference) and by almost two times in the case of $P$. ostreatus. As regards A. cylindracea especially, all TPOWM amended substrates (with the exception of raw TPOMW 60\%) performed significantly better than the control. As regards Pleurotus spp., raw TPOMW 40\% and composted TPOMW 60\% presented relatively inferior productivity values than the rest of the treatments, whereas raw TPOMW 20\% performed equally well or even slightly better (P. ostreatus) than wheat straw. Lastly, raw TPOMW $60 \%$ performed poorly.

The total phenolic content and antioxidant activity of the four strains examined were not significantly different among the various TPOMW substrates examined ranging from 


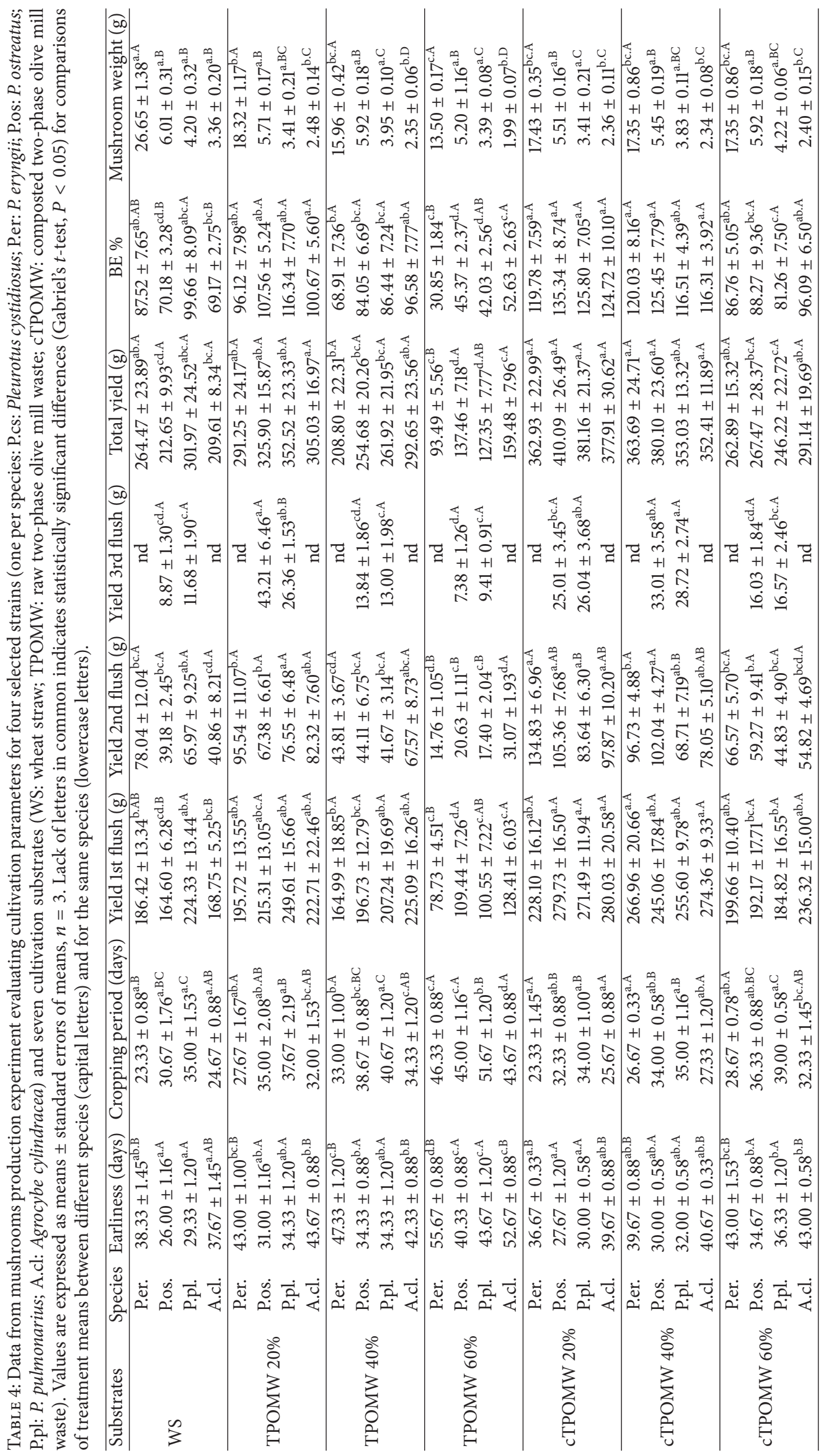




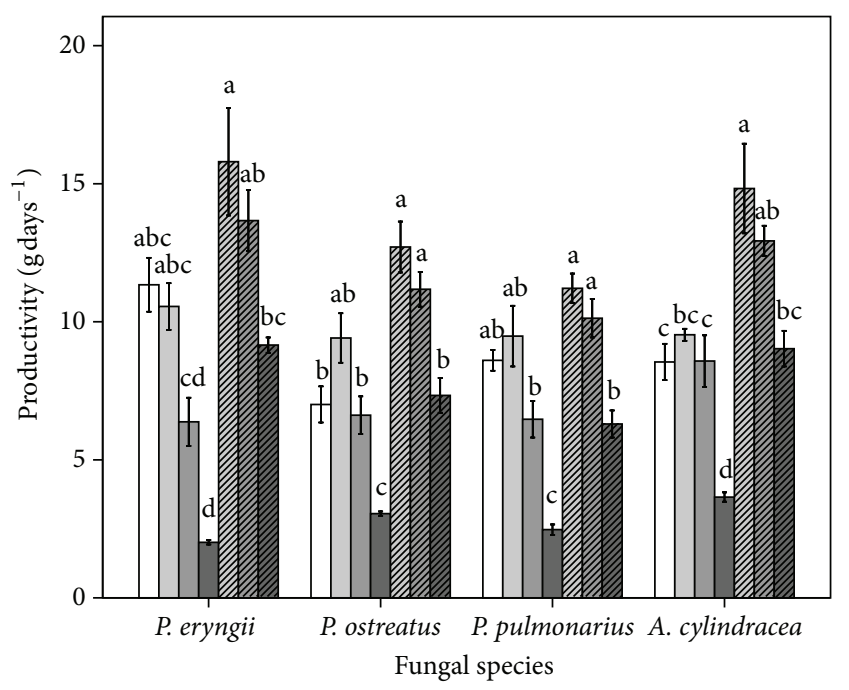

Substrate ․ Wheat straw

TPOMW $20 \%$

ㅁ TPOMW $40 \%$

TPOMW 60\%

FIgURe 5: Productivity (ratio of total yield over the duration of the cropping period) for four mushroom species growing on seven cultivation substrates (TPOMW: raw two-phase olive mill waste; cTPOMW: composted two-phase olive mill waste). Values ( g days $^{-1}$ ) are expressed as means \pm standard errors of means, $n=3$. Lack of letters in common indicates statistically significant differences (Gabriel's $t$-test, $P<0.05$ ) among substrates for each species examined.

0.10 to $0.17 \mathrm{mg} \mathrm{mL}^{-1}$ gallic acid equivalents (raw TPOMW $40 \%$ and composted TPOMW $60 \%$ presenting the highest contents). Similarly, the DPPH scavenging capacity did not differ significantly among cultivation substrates; however, the $P$. eryngii strain demonstrated higher antioxidant values reaching up to $84 \%$ (compared to A. cylindracea's 59\%, $P$. ostreatus's $68 \%$, and P. pulmonarius's $72 \%$ ).

\section{Discussion}

For all strains tested, mycelium grew equally well or (in most cases) significantly better in composted TPOMW than in noncomposted substrates (in comparisons made between equal rates of supplementation in respect to wheat-straw). Similarly, and most importantly still, addition of composted TPOMW $20 \%$ and $40 \%$ into the growth substrate resulted in high mycelium growth rates accompanied by notably better earliness values in respect to the control (wheat straw). It is evident that the TPOMW pretreatment through the composting process alleviated (at least in part) the toxicity of the effluent while at the same time provided readily available nutrients through the action of the thermophilic microbiota as it was also demonstrated by previous studies on TPOMW composting $[3,5,8,43]$. Indeed, phytotoxicity tests performed with both raw and composted TPOMW demonstrated that toxicity of the latter was significantly reduced. Moreover, composting might have also ensured the presence of inducer compounds, which especially in the case of the white-rot fungi enhance the activity of their lignindegrading system $[44,45]$. In previous pertinent studies, the use of OMWW either as ingredient or just as wetting agent of Pleurotus cultivation media [16-18] contributed at maintaining $\mathrm{pH}$ values at levels close to those commonly used for its commercial production (i.e., 6.0-7.0). This work revealed that, although composted TPOMW substrates possessed a higher $\mathrm{pH}$ (i.e., 7.5-8.0), satisfactory growth of mycelia and high mushroom yields were achieved vis-àvis raw TPOMW and wheat-straw media with lower $\mathrm{pH}$ values. Similar observations on the successful use of other mushroom substrates with $\mathrm{pH}$ values of up to 7.5 were also made by Yildiz et al. [46].

The "race" tubes evaluation excluded the subsequent use of one species (P. cystidiosus) due to the significantly slower colonization rates it demonstrated. In addition, eight out of the twelve strains initially screened for the rest of the four species examined were also abandoned. Hence, cultivation trials were further performed with the four most efficient (faster growing and earlier in producing mushroom primordia) strains of $A$. cylindracea, P. eryngii, P. ostreatus, and P. pulmonarius on seven cultivation substrates. In general, higher TPOMW supplementation resulted in longer colonization periods despite the fact that differences noted for earliness were not statistically significant. However, similar effects were also reported in the past when various types of olive mill wastes were added to Pleurotus cultivation substrates resulting in delayed formation of primordia $[17,18,20]$. In all these cases, increase in olive waste amendment has a distinct adverse effect on earliness; interestingly enough, this seems to be (at least partly) mitigated when composted TPOMW was used instead. Furthermore, earliness values observed in this work were much lower than those reported when $P$. eryngii and $P$. pulmonarius were examined on extracted olive press cake supplemented with OMWW [18] or when A. cylindracea was examined on cotton waste, wheat straw, and peanut shells [25]. On the other hand, they are similar to those reported on raw TPOMW for P. ostreatus and P. pulmonarius [20] and on cotton waste, wheat straw and peanut shells for $P$. ostreatus, $P$. pulmonarius, and P. eryngii [25].

TPOMW-based substrates supported high yields for all species examined. The highest BE values were obtained from the composted TPOMW 20\% medium, which performed distinctly better for all species examined in comparison with the control treatment (albeit differences were not always statistically significant due to high errors of the means). Almost equally satisfactory was the performance of raw TPOMW 20\% and composted TPOMW 40\% substrates, whereas even in higher TPOMW amended treatments (i.e., raw TPOMW 40\% and composted TPOMW 60\%) yields were comparable to those of the control, and only the raw TPOMW 60\% underperformed. The values obtained are markedly higher than those reported in the literature. In the only previous study on the use of raw TPOMW as oyster mushroom cultivation substrate [20], BE values of as high as $85 \%$ were observed in substrates containing $50 \%$ effluent, whereas at higher concentrations they decreased 
rather sharply (64\% at TPOMW 60\%). Values reported in the present work are considerably higher as regards the performance at lower raw TPOMW concentrations (i.e., 20\% and $40 \%$ ) but especially when composted media were used. However, results of both studies seem to coincide as concerns the decrease in mushroom yields that becomes significant at levels of TPOMW supplementation exceeding 50\%.

Moreover, BEs noted in the present study are higher than most of those obtained through the use of other substrates. In the past, $P$. eryngii production on either supplemented $[25,27,47]$ or amended with a casing layer $[48,49]$ substrates presented BEs of $7-88 \%$ and $47-115 \%$, respectively. The outcome of the present work revealed that addition of composted TPOMW enhanced considerably the performance of wheat straw based substrates by reaching BE values of $120 \%$. More importantly, this result was obtained without addition of rich in nitrogen (e.g., soybean flour) and/or delayed-release nutrients and without the use of any casing material which when applied is reported to increase significantly yields in $P$. eryngii cultivation $[49,50]$.

Similarly, $P$. ostreatus and $P$. pulmonarius yields in TPOMW amended substrates were very high and in the case of the former species they almost doubled those measured in wheat straw. Both strains presented BEs exceeding $100 \%$ in three different TPOMW media (raw 20\%, and composted $20 \%$ and $40 \%$ ), that is, $108-135 \%$. BEs reported in previous studies demonstrated a high variability depending on the nature of substrate, type of supplementation, and the strain(s) used; still, the respective values reported are in most cases lower than those achieved through the use of TPOMW containing media. Hence, for P. ostreatus, values ranged from $0 \%$ to $96 \%$ in wheat straw amended with solid waste from anaerobic digestion of litter from broiler chickens, $14 \%$ in peanut shells, $4-61 \%$ in different types of sawdust, $8-46 \%$ in wheat straw wetted by olive mill wastewater, 37-79\% in vineyard pruning and grape pomace, 50-94\% in wheat straw, $72-87 \%$ in coffee pulp, to $71-117 \%$ in cotton wastes $[16,24,25,51-53]$. It is of interest that even when a substrate containing sunflower seed hulls received supplementation with optimized levels of $\mathrm{Mn}(\mathrm{II})$ and/or $\mathrm{NH}_{4}$, BE values for $P$. ostreatus did not exceed $112 \%$ [54]. As regards $P$. pulmonarius, the BEs ranged from $19 \%$ in peanut shells, 38-63\% in vineyard pruning and grape pomace, $50-81 \%$ in coffee pulp, $93-97 \%$ in cotton waste, to $66-123 \%$ in wheat straw $[25,51,52]$.

Most of the cultivation studies conducted so far on A. cylindracea focused on the use of wheat straw usually supplemented with various nitrogen-rich materials, while alternative substrates were only occasionally evaluated, for example, willow sawdust, poultry litter, cotton waste, and peanut shells $[25,29,55]$. In general, amended wheat straw based media supported high yields either when soybean flour was added (BE: 138-179\% within 53-64 days of cropping period corresponding to three production flushes) [29] or when solid waste from anaerobic digestion of poultry litter was used (BE: 106\% over a 115-day fruiting cycle corresponding to five flushes) [55]. On the other hand, this work evaluated for the first time the potential use of olive mill wastes as substrate for $A$. cylindracea cultivation; both raw and composted TPOMW (20\% and 40\%) based media exhibited significantly higher BE than the wheat straw control ranging from $97 \%$ to $125 \%$ within a cropping period of 26 to 34 days including two production flushes only.

Substrate supplementation represents a key issue in developing successful solid-state fermentation of various lignocellulosic materials for mushroom cultivation. In the past, the amendment of straw-based Pleurotus spp. and A. cylindracea substrates with different nitrogen-rich compounds received much attention $[27,29,54,56]$. Despite the fact that addition of such materials clearly results in higher yields, their use is also linked with increased possibility of compromising mushroom production due to the fast rise in substrate temperature because of enhanced fungal metabolic activities triggered by the presence of extra nitrogen $[56,57]$ and/or to the significantly higher contamination risks by competitor microorganisms $[46,58]$.

If TPOMW is considered as a supplement to conventional wheat straw substrates, the evaluation of its effects on mushroom production demonstrates that its presence at rather low concentrations (i.e., 20\% w/w) significantly enhanced BE, while it had no effect on earliness, size of basidiomata, and quality traits (phenolic and antioxidants content, shape of mushrooms). Furthermore, it seems that the presence of composted TPOMW promotes high mushroom yields through the enrichment of the cultivation media with several macro- and micronutrients which are otherwise not provided (in the conventional wheat straw substrates). More interestingly still this type of supplementation is considered advantageous as opposed to that provided by other nitrogen rich compounds, which are ordinarily used as amendments in mushroom cultivation (e.g., soybean flour). Although this latter type of material provides readily assimilated forms of nutrients whose impacts are easily identifiable on the performance of the subsequent mushroom crop, at the same time its use presents significant drawbacks as previously explained. In contrast, a TPOMW-based cultivation medium maintains most of the inherent advantageous properties of a typical plain lignocellulosic substrate for the selective growth of mushroom species [59]. Since it possesses a rather high content in complex organic compounds, it provides a very important competitive advantage for the cultivated mushroom, especially under commercial cultivation conditions. Along the same line of arguments, Altieri et al. [19] used a substrate mainly composed of destined olive husk taken from two-phase olive mills for commercial-scale cultivation of Agaricus bisporus and demonstrated that this material presented improved selectivity and hence better protection against competitors. At the same time it possessed higher content in organic nitrogen and enhanced organic matter degradation in comparison to the conventional wheat straw plus chicken manure compost.

Correlation of substrates contents versus cultivation parameters examined in the frame of the present study revealed that substrates hemicellulose content was negatively correlated with mycelium growth rates and BEs $\left(r^{2}: 0.75-\right.$ 0.91 and $0.59-0.88$, resp. $)$ and positively with earliness $\left(r^{2}\right.$ : 0.81-0.95). Furthermore, lignin content presented a negative correlation with earliness $\left(r^{2}: 0.80-0.94\right)$ in contrast 
to what was observed for cellulose : lignin ratio $\left(r^{2}: 0.60-\right.$ $0.83)$. Lastly, $\mathrm{C}: \mathrm{N}$ and cellulose $:$ lignin ratios revealed a positive correlation with mushroom weight for $P$. eryngii and A. cylindracea strains $\left(r^{2}: 0.83-0.85\right.$ and $0.84-0.85$, resp.). As regards $A$. cylindracea especially, cellulose: lignin ratio was positively correlated with mycelium growth rate which is in accordance with earlier observations on other cultivation substrates indicating that this species preferentially consumes cellulose $[25,55]$. It is worth mentioning that $\mathrm{C}: \mathrm{N}$ ratio was not correlated with mycelium growth rates and BEs as it was reported in a previous study [25], and this could be attributed to the fact that although increased TPOMW supplementation results in higher $\mathrm{N}$ (and other nutrients) content, at the same time the higher toxicity of this material has adverse effects which progressively eliminate its positive influence. This was evidenced when the raw TPOMW 60\% treatment was excluded from the correlation analysis, which resulted at obtaining relatively high correlation values for $\mathrm{C}: \mathrm{N}$ versus growth rates and BEs (e.g., 0.63-0.68 and 0.77-0.92, resp.).

The issue of the final product quality, especially when mushrooms are cultivated on such a type of substrates is also of importance. In the frame of this study, harvested mushrooms were examined for any deformations or abnormalities in shape or colour due to the TPOMW amendments. Moreover, their content in phenolic compounds was assessed with respect to that the level of TPOMW supplementation of their growing substrate received. As regards their appearance, no deformations were observed apart from the pilei in Pleurotus strains, which presented slightly lighter colours in increased TPOMW concentrations (40\% and 60\% rates). This observation is in accordance with the findings of Ruiz-Rodriguez et al. [20] and might be attributed to hindered production of melanin-related pigments. However, such colour variations in Pleurotus pilei are common even among strains of the same species, while they also appear under the influence of different environmental parameters [22]. Hence, they do not constitute an adverse quality trait for the product itself or for its acceptance by the market. Most importantly, the total phenolic content and antioxidant activity values were not statistically different in comparisons among straw and TPOMW based substrates indicating thus that no inhibition of oxidative enzymes or absorption of phenol-related compounds occurred. These results confirm and expand the conclusions drawn by a previous pertinent study employing P. ostreatus and P. pulmonarius strains [20].

Moreover, the mushroom cultivation process developed on TPOMW-based media, apart from providing an edible product of high added value, can also lead to the exploitation of the spent substrate. Treatment of TPOMW with mushroom fungi could constitute an alternative economical method in order to convert olive wastes into valuable amendments for agricultural soils or constituents of animal feed. The final by-product has a low content in phenolic compounds through the action of fungal ligninolytic enzymes leading to a significant decrease of biotoxicity $[13,38,60]$, while it presents lower values in total organic carbon, humic acids and lignocellulosic compounds, lower $\mathrm{C}: \mathrm{N}$ ratio, and increased content in nutrients including proteins $[19,61,62]$.
In conclusion, productivity of all four mushroom species examined was found to be the highest when wheat straw (the basic component for most mushroom production substrates) was supplemented with 20-40\% composted TPOMW (or $20 \%$ raw TPOMW). Only when supplementation exceeded $60 \%$ for raw TPOMW, a negative impact was noted on mushroom yields, which could be attributed to the biotoxic effect of the effluent. In fact, the difference observed in comparisons between raw and composted TPOMW is directly related with the composting process itself since material subjected to the latter type of treatment was significantly detoxified as the phytotoxicity tests revealed. Hence, TPOMW-based media are promising alternative substrates for the cultivation of Pleurotus spp. and A. cylindracea. The production process is in need of relatively minor modifications aiming mainly at reducing the incubation period and the rather high variability observed in mushroom productivity. In addition, of importance is the exploitation of a waste material which until now is associated with significant problems regarding its safe environmental disposal. Moreover, the valorization of new substrates for the cultivation of choice mushroom species (some of which are still not widely cultivated in Europe and hence their commercial production could lead to a muchsought after market diversification) is of further interest.

\section{Acknowledgments}

This work was partly funded by PEFANIS S. A. and by the research project Metagenomics of Ligninolytic Microorganisms-Bioconversion of Plant By-Products into High-Added Value Products (Thalis Programme, MIS 377062).

\section{References}

[1] G. Ouzounidou, G. I. Zervakis, and F. Gaitis, "Raw and microbiologically detoxified olive mill waste and their impact on plant growth," Terrestrial and Aquatic Environmental Toxicology, vol. 4, no. 1, pp. 21-38, 2010.

[2] A. Roig, M. L. Cayuela, and M. A. Sánchez-Monedero, "An overview on olive mill wastes and their valorisation methods," Waste Management, vol. 26, no. 9, pp. 960-969, 2006.

[3] J. A. Alburquerque, J. Gonzálvez, D. García, and J. Cegarra, "Measuring detoxification and maturity in compost made from "alperujo", the solid by-product of extracting olive oil by the two-phase centrifugation system," Chemosphere, vol. 64, no. 3, pp. 470-477, 2006.

[4] J. A. Alburquerque, J. Gonzálvez, G. Tortosa, G. A. Baddi, and J. Cegarra, "Evaluation of "alperujo" composting based on organic matter degradation, humification and compost quality," Biodegradation, vol. 20, no. 2, pp. 257-270, 2009.

[5] J. A. Alburquerque, J. Gonzálvez, D. García, and J. Cegarra, "Composting of a solid olive-mill by-product ("alperujo") and the potential of the resulting compost for cultivating pepper under commercial conditions," Waste Management, vol. 26, no. 6, pp. 620-626, 2006.

[6] C. Borrero, I. Trillas, and M. Avilés, "Carnation Fusarium wilt suppression in four composts," European Journal of Plant Pathology, vol. 123, no. 4, pp. 425-433, 2009.

[7] S. Ntougias, N. Kavroulakis, G. I. Zervakis, C. Ehaliotis, and K. K. Papadopoulou, "Composts deriving from two-phase 
olive mill wastes (alpeorujo) may be used in potting media and suppress soil-borne pathogens," in Proceedings of the 4th European Bioremediation Conference (EBC '08), N. Kalogerakis, F. Fava, and S. A. Banwart, Eds., Chania, Crete, 2008, ID169.

[8] G. I. Zervakis, S. Ntougias, G. Ouzounidou, and F. Gaitis, "Treatment of two-phase olive mill wastes through commercialscale composting and evaluation of the end-product for agricultural use," in Proceedings of the 12th International Conference on Environmental Science and Technology (CEST '11), T. D. Lekkas, Ed., pp. A2083-A2089, Global NEST, 2011.

[9] E. Aranda, I. Sampedro, J. A. Ocampo, and I. García-Romera, "Phenolic removal of olive-mill dry residues by laccase activity of white-rot fungi and its impact on tomato plant growth," International Biodeterioration and Biodegradation, vol. 58, no. 3-4, pp. 176-179, 2006.

[10] A. Linares, J. M. Caba, F. Ligero, T. De la Rubia, and J. Martínez, "Detoxification of semisolid olive-mill wastes and pine-chip mixtures using Phanerochaete flavido-alba," Chemosphere, vol. 51, no. 9, pp. 887-891, 2003.

[11] I. Sampedro, S. Marinari, A. D’Annibale, S. Grego, J. A. Ocampo, and I. García-Romera, "Organic matter evolution and partial detoxification in two-phase olive mill waste colonized by whiterot fungi," International Biodeterioration and Biodegradation, vol. 60, no. 2, pp. 116-125, 2007.

[12] H. Lakhtar, M. Ismaili-Alaoui, A. Philippoussis, I. PerraudGaime, and S. Roussos, "Screening of strains of Lentinula edodes grown on model olive mill wastewater in solid and liquid state culture for polyphenol biodegradation," International Biodeterioration and Biodegradation, vol. 64, no. 3, pp. 167-172, 2010.

[13] S. Ntougias, P. Baldrian, C. Ehaliotis et al., "Biodegradation and detoxification of olive mill wastewater by selected strains of the mushroom genera Ganoderma and Pleurotus," Chemosphere, vol. 88, no. 5, pp. 620-626, 2012.

[14] G. Olivieri, A. Marzocchella, P. Salatino, P. Giardina, G. Cennamo, and G. Sannia, "Olive mill wastewater remediation by means of Pleurotus ostreatus," Biochemical Engineering Journal, vol. 31, no. 3, pp. 180-187, 2006.

[15] E. Sanjust, R. Pompei, A. Rescigno, A. Rinaldi, and M. Ballero, "Olive milling wastewater as a medium for growth of four Pleurotus species," Applied Biochemistry and Biotechnology, vol. 31, no. 3, pp. 223-235, 1991.

[16] E. Kalmis, N. Azbar, H. Yildiz, and F. Kalyoncu, "Feasibility of using olive mill effluent (OME) as a wetting agent during the cultivation of oyster mushroom, Pleurotus ostreatus, on wheat straw," Bioresource Technology, vol. 99, no. 1, pp. 164-169, 2008.

[17] E. Kalmiş and S. Sargin, "Cultivation of two Pleurotus species on wheat straw substrates containing olive mill waste water," International Biodeterioration and Biodegradation, vol. 53, no. 1, pp. 43-47, 2004.

[18] G. Zervakis, P. Yiatras, and C. Balis, "Edible mushrooms from olive oil mill wastes," International Biodeterioration and Biodegradation, vol. 38, no. 3-4, pp. 237-243, 1996.

[19] R. Altieri, A. Esposito, F. Parati, A. Lobianco, and M. Pepi, "Performance of olive mill solid waste as a constituent of the substrate in commercial cultivation of Agaricus bisporus," International Biodeterioration and Biodegradation, vol. 63, no. 8, pp. 993-997, 2009.

[20] A. Ruiz-Rodriguez, C. Soler-Rivas, I. Polonia, and H. J. Wichers, "Effect of olive mill waste (OMW) supplementation to Oyster mushrooms substrates on the cultivation parameters and fruiting bodies quality," International Biodeterioration and Biodegradation, vol. 64, no. 7, pp. 638-645, 2010.
[21] G. Zervakis, "Cultivation of the king-oyster mushroom Pleurotus eryngii (DC.:Fr.) Quél. on substrates deriving from the oliveoil industry," International Journal of Medicinal Mushrooms, vol. 7, no. 3, pp. 486-487, 2005.

[22] G. Zervakis and C. Balis, "A pluralistic approach in the study of Pleurotus species with emphasis on compatibility and physiology of the European morphotaxa," Mycological Research, vol. 100, no. 6, pp. 717-731, 1996.

[23] G. I. Zervakis, J. Moncalvo, and R. Vilgalys, "Molecular phylogeny, biogeography and speciation of the mushroom species Pleurotus cystidiosus and allied taxa," Microbiology, vol. 150, no. 3, pp. 715-726, 2004.

[24] M. Obodai, J. Cleland-Okine, and K. A. Vowotor, "Comparative study on the growth and yield of Pleurotus ostreatus mushroom on different lignocellulosic by-products," Journal of Industrial Microbiology and Biotechnology, vol. 30, no. 3, pp. 146-149, 2003.

[25] A. Philippoussis, G. Zervakis, and P. Diamantopoulou, "Bioconversion of agricultural lignocellulosic wastes through the cultivation of the edible mushrooms Agrocybe aegerita, Volvariella volvacea and Pleurotus spp.", World Journal of Microbiology and Biotechnology, vol. 17, no. 2, pp. 191-200, 2001.

[26] J. Poppe and M. Höfte, “Twenty wastes for twenty cultivated mushrooms," Mushroom Science, vol. 14, pp. 171-179, 1995.

[27] A. E. Rodriguez Estrada and D. J. Royse, "Yield, size and bacterial blotch resistance of Pleurotus eryngii grown on cottonseed hulls/oak sawdust supplemented with manganese, copper and whole ground soybean," Bioresource Technology, vol. 98, no. 10, pp. 1898-1906, 2007.

[28] M. Uhart and E. Albertó, "Morphologic characterization of Agrocybe cylindracea (Basidiomycetes, Agaricales) from America, Europe and Asia," Revista Mexicana de Micologia, vol. 24, pp. 18-26, 2007.

[29] M. Uhart, J. M. Piscera, and E. Albertó, "Utilization of new naturally occurring strains and supplementation to improve the biological efficiency of the edible mushroom Agrocybe cylindracea," Journal of Industrial Microbiology and Biotechnology, vol. 35, no. 6, pp. 595-602, 2008.

[30] S. Tsai, S. Huang, S. Lo, T. Wu, P. Lian, and J. Mau, "Flavour components and antioxidant properties of several cultivated mushrooms," Food Chemistry, vol. 113, no. 2, pp. 578-584, 2009.

[31] S. P. Wasser and A. L. Weis, "Therapeutic effects of substances occurring in higher basidiomycetes mushrooms: a modern perspective," Critical Reviews in Immunology, vol. 19, no. 1, pp. 65-96, 1999.

[32] Y. Zhang, G. L. Mills, and M. G. Nair, "Cyclooxygenase inhibitory and antioxidant compounds from the fruiting body of an edible mushroom, Agrocybe aegerita," Phytomedicine, vol. 10, no. 5, pp. 386-390, 2003.

[33] C. Zhao, H. Sun, X. Tong, and Y. Qi, "An antitumour lectin from the edible mushroom Agrocybe aegerita," Biochemical Journal, vol. 374, no. 2, pp. 321-327, 2003.

[34] G. Zervakis, A. Philippoussis, S. Ioannidou, and P. Diamantopouiou, "Mycelium growth kinetics and optimal temperature conditions for the cultivation of edible mushroom species on lignocellulosic substrates," Folia Microbiologica, vol. 46, no. 3, pp. 231-234, 2001.

[35] P. J. van Soest and R. H. Wine, "Determination of lignin and cellulose in acid-detergent fiber with permanganate," Journal of AOAC International, vol. 51, pp. 780-785, 1968.

[36] M. M. Heckman and S. A. Lane, "Comparison of dietary fiber methods for foods," Journal of the Association of Official Analytical Chemists, vol. 64, no. 6, pp. 1339-1343, 1981. 
[37] P. J. Van Soest and R. H. Wine, "Use of detergents in the analysis of fibrous feeds. IV. Determination of plant cell-wall constituents," Journal of the Association of Official Analytical Chemists, vol. 50, pp. 50-55, 1967.

[38] S. Ntougias, F. Gaitis, P. Katsaris, S. Skoulika, N. Iliopoulos, and G. I. Zervakis, "The effects of olives harvest period and production year on olive mill wastewater properties-Evaluation of Pleurotus strains as bioindicators of the effluent's toxicity," Chemosphere, vol. 92, no. 4, pp. 399-405, 2013.

[39] V. L. Singleton and J. A. Rossi, "Colorimetry of total phenolics with phosphomolybdic phosphotungstic acid reagents," American Journal of Enology and Viticulture, vol. 16, no. 3, pp. 144-158, 1965.

[40] J. Mau, H. Lin, and S. Song, "Antioxidant properties of several specialty mushrooms," Food Research International, vol. 35, no. 6, pp. 519-526, 2002.

[41] F. Zucconi, M. Forte, A. Monaco, and M. De Bertoldi, "Biological evaluation of compost maturity," BioCycle, vol. 22, no. 4, pp. 27-29, 1981.

[42] G. I. Zervakis and G. Koutrotsios, "Production of edible mushroom biomass on solid wastes and by-products of olive-oil processing," in Proceedings of the 5th European Bioremediation Conference (EBC '11), N. Kalogerakis and F. Fava, Eds., Chania, Crete, 2011, ID218.

[43] J. A. Alburquerque, J. Gonzálvez, D. García, and J. Cegarra, "Effects of a compost made from the solid by-product ("alperujo") of the two-phase centrifugation system for olive oil extraction and cotton gin waste on growth and nutrient content of ryegrass (Lolium perenne L.)," Bioresource Technology, vol. 98, no. 4, pp. 940-945, 2007.

[44] J. A. Bumpus, M. Tien, D. Wright, and S. D. Aust, "Oxidation of persistent environmental pollutants by a white rot fungus," Science, vol. 228, no. 4706, pp. 1434-1436, 1985.

[45] B. D. Faison and T. K. Kirk, "Factors involved in the regulation of a ligninase activity in Phanerochaete chrysosporium," Applied and Environmental Microbiology, vol. 49, no. 2, pp. 299-304, 1985.

[46] S. Yildiz, Ü. C. Yildiz, E. D. Gezer, and A. Temiz, "Some lignocellulosic wastes used as raw material in cultivation of the Pleurotus ostreatus culture mushroom," Process Biochemistry, vol. 38, no. 3, pp. 301-306, 2002.

[47] R. M. Gaitán-Hernández, "Evaluacion in vitro del hongo comestible Pleurotus eryngii efecto de diferentes suplementos organicos en el crecimiento micelial y produccion de cuerpos fructiferos," Revista Mexicana de Microbiologia, vol. 21, pp. 7784, 2005.

[48] J. T. Peng, "The cultivation of Pleurotus eryngii (DC.:Fr.) Quel. on rice straw substrate," Journal of Agricultural Research of China, vol. 45, pp. 382-387, 1996.

[49] A. E. Rodriguez Estrada, M. D. M. Jimenez-Gasco, and D. J. Royse, "Improvement of yield of Pleurotus eryngii var. eryngii by substrate supplementation and use of a casing overlay," Bioresource Technology, vol. 100, no. 21, pp. 5270-5276, 2009.

[50] G. Zervakis and G. Venturella, "Mushroom breeding and cultivation enhances ex situ conservation of Mediterranean Pleurotus taxa," in Managing Plant Genetic Diversity, J. M. M. Engels, Ed., pp. 351-358, CAB Publishing, Oxford, UK, 2002.

[51] D. Salmones, G. Mata, and K. N. Waliszewski, "Comparative culturing of Pleurotus spp. on coffee pulp and wheat straw: biomass production and substrate biodegradation," Bioresource Technology, vol. 96, no. 5, pp. 537-544, 2005.
[52] A. Sánchez, F. Ysunza, M. J. Beltran-García, and M. Esqueda, "Biodegradation of viticulture wastes by Pleurotus a source of microbial and human food and its potential use in animal feeding," Journal of Agricultural and Food Chemistry, vol. 50, no. 9, pp. 2537-2542, 2002.

[53] O. S. Isikhuemhen and N. A. Mikiashvilli, "Lignocellulolytic enzyme activity, substrate utilization, and mushroom yield by Pleurotus ostreatus cultivated on substrate containing anaerobic digester solids," Journal of Industrial Microbiology and Biotechnology, vol. 36, no. 11, pp. 1353-1362, 2009.

[54] N. R. Curvetto, D. Figlas, R. Devalis, and S. Delmastro, "Growth and productivity of different Pleurotus ostreatus strains on sunflower seed hulls supplemented with N-NH4+ and/or Mn(II)," Bioresource Technology, vol. 84, no. 2, pp. 171-176, 2002.

[55] O. S. Isikhuemhen, N. A. Mikiashvili, and V. Kelkar, "Application of solid waste from anaerobic digestion of poultry litter in Agrocybe aegerita cultivation: mushroom production, lignocellulolytic enzymes activity and substrate utilization," Biodegradation, vol. 20, no. 3, pp. 351-361, 2009.

[56] R. C. Upadhyay, R. N. Verma, S. K. Singh, and M. C. Yadav, "Effect of organic nitrogen supplementation in Pleurotus species," in Mushroom Biology and Mushroom Products, J. E. Sánchez and D. J. Royse, Eds., pp. 225-232, UAEM, Toluca, Mexico, 2002.

[57] A. Overstijns, "Influence of corn steep liquor in Pleurotus substrate," Mushroom Information, vol. 12, pp. 6-11, 1995.

[58] K. Gunasegaran and K. M. Graham, "Effect of organic additives on yield of the Phoenix mushroom grown on cellulose waste," Mushroom Journal for the Tropics, vol. 7, pp. 101-106, 1987.

[59] J. L. M. Huntjens, "Amino acid composition of humic acid-like polymers produced by streptomycetes and of humic acids from pasture and arable land," Soil Biology and Biochemistry, vol. 4, no. 3, pp. 339-345, 1972.

[60] G. Aggelis, C. Ehaliotis, F. Nerud, I. Stoychev, G. Lyberatos, and G. Zervakis, "Evaluation of white-rot fungi for detoxification and decolorization of effluents from the green olive debittering process," Applied Microbiology and Biotechnology, vol. 59, no. 23, pp. 353-360, 2002.

[61] G. Koutrotsios, K. C. Mountzouris, and G. I. Zervakis, "Cultivation of Pleurotus ostreatus and Agrocybe cylindracea on various lignocellulosic by-products," in Proceedings of the IAMAW 1st International Workshop Valorization of Mediterranean Biowastes and Effluents (IAMAW '12), pp. 30-31, Santarem, Portugal, 2012.

[62] M. Saavedra, E. Benitez, C. Cifuentes, and R. Nogales, "Enzyme activities and chemical changes in wet olive cake after treatment with Pleurotus ostreatus or Eisenia fetida," Biodegradation, vol. 17, no. 1, pp. 93-102, 2006. 

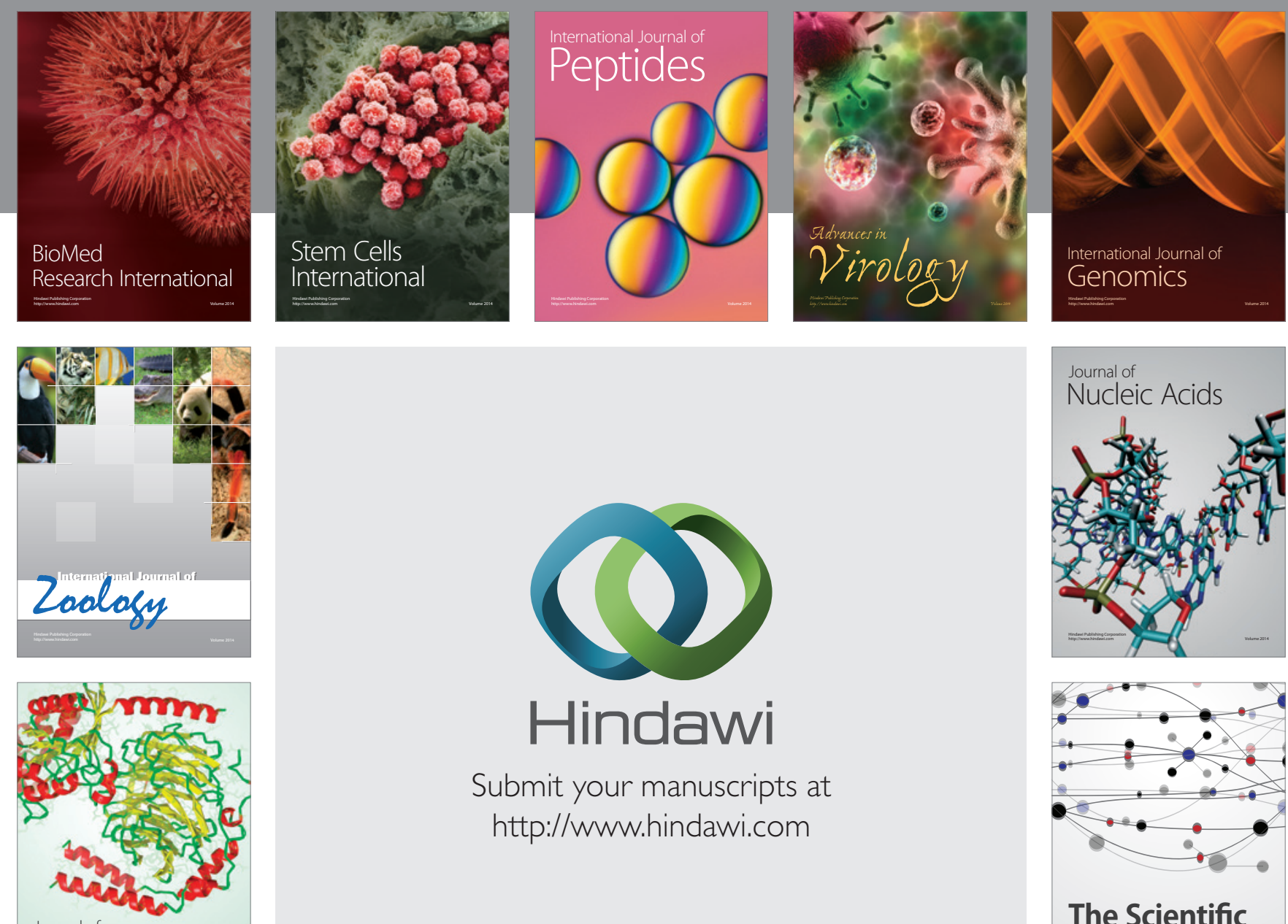

Submit your manuscripts at

http://www.hindawi.com

Journal of
Signal Transduction
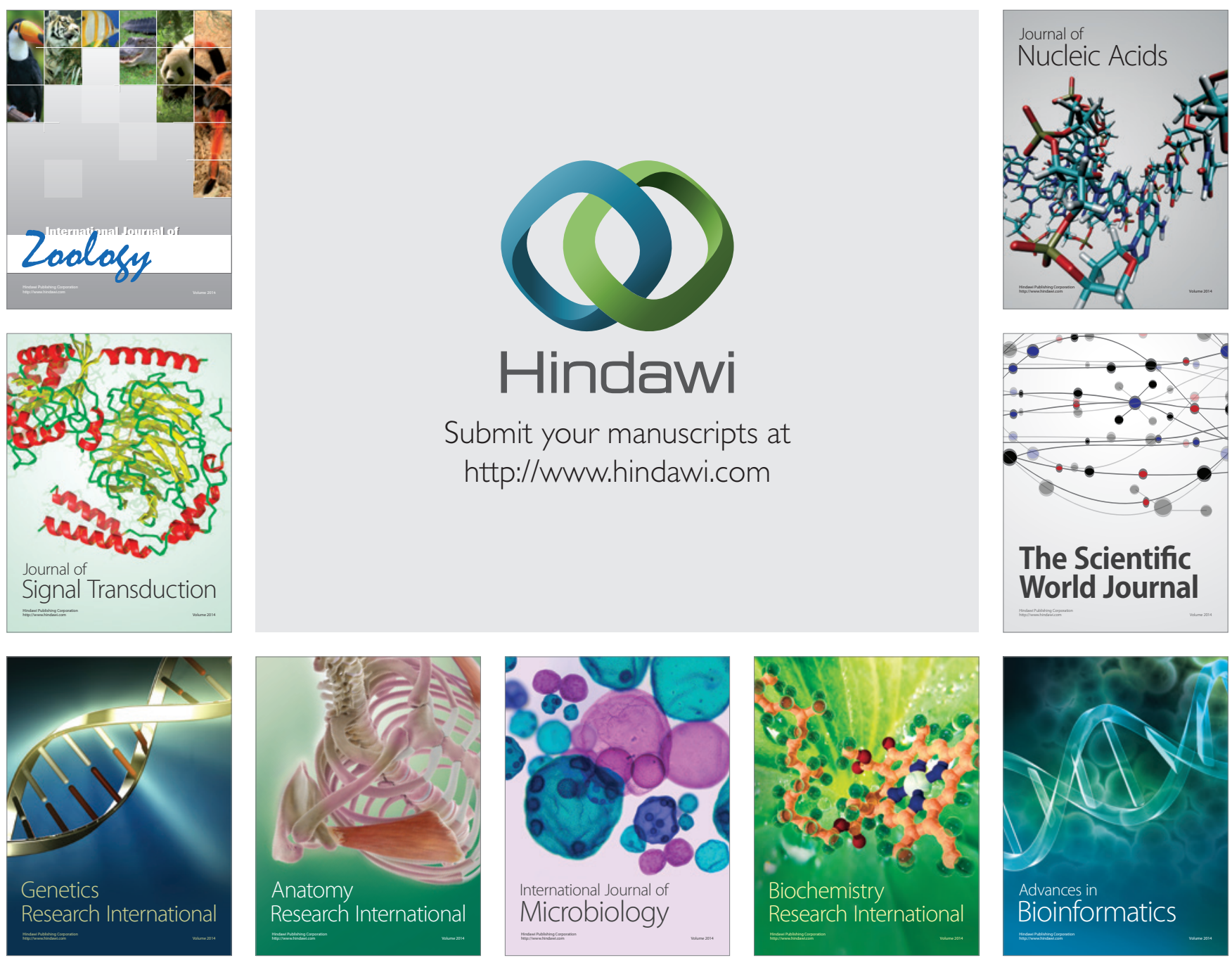

The Scientific World Journal
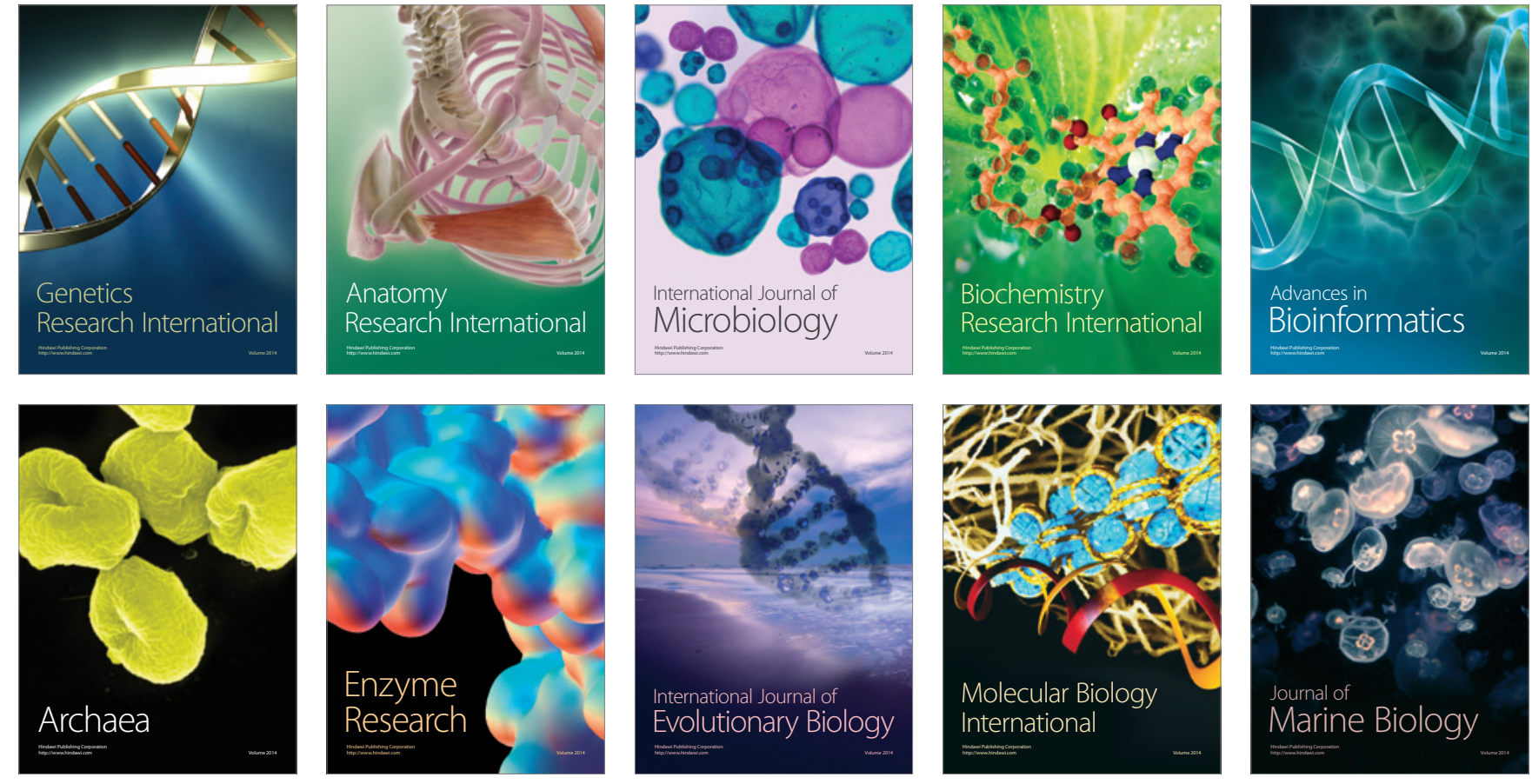